\title{
Hydrogen Absorption Rate into Fe with Rust Layer Containing NaCl during Atmospheric Corrosion in Humidity-controlled Air
}

\author{
Takumi HARUNA, ${ }^{1 *}{ }^{1}$ Yuki SHOJI') and Youhei HIROHATA ${ }^{1)}$ \\ 1) Faculty of Chemistry, Materials and Bioengineering, Kansai University, 3-3-35 Yamate-cho, Suita, Osaka, $564-8680$ Japan. \\ 2) Student in Graduate School of Science and Engineering, Kansai University, 3-3-35 Yamate-cho, Suita, Osaka, 564-8680 \\ Japan.
}

(Received on January 12, 2020; accepted on March 3, 2020; J-STAGE Advance published date: May 28, 2020)

\begin{abstract}
The research aimed to detect the rate of hydrogen absorption into Fe with rust layer during atmospheric corrosion in humidity-controlled air, and to realize the effect of relative humidity $(\mathrm{RH})$ on hydrogen absorption rate. One side of an Fe plate specimen was covered by electrochemical Ni plate and the other side was covered with rust layer containing $\mathrm{NaCl}$. The specimen was set between the double cells for electrochemical hydrogen permeation test. The cell for hydrogen detection was filled with $1 \mathrm{kmol} \cdot \mathrm{m}^{-3} \mathrm{NaOH}$ solution and the $\mathrm{Ni}$ side of the specimen was subjected to $0 \mathrm{~V}_{\mathrm{Ag} / \mathrm{AgCl}}$ in the solution. The cell for hydrogen absorption was filled with the air with a controlled $\mathrm{RH}$ to make the rust layer side corrode. During the corrosion, a hydrogen absorption current and an $\mathrm{RH}$ were continuously monitored. In the tests, the following results were obtained. In the region of $\mathrm{RH}$ between 42 and $74 \%$, a hydrogen absorption rate increased with an increase in an $\mathrm{RH}$. At an $\mathrm{RH}$ of $80 \%$, a hydrogen absorption rate suddenly decreased. In the region of $\mathrm{RH}$ between 80 to 95\%, a hydrogen absorption rate again increased with an increase in an $\mathrm{RH}$. The $\mathrm{pH}$ in the rust layers during the corrosion under the tested $\mathrm{RH}$ range was estimated to be 4.2 and 4.3 , slightly acidic.
\end{abstract}

KEY WORDS: hydrogen absorption rate; iron; rust layer; atmospheric corrosion; relative humidity; solution layer; deliquescence; Fick's first law; acidification.

\section{Introduction}

It is well known that the steels with higher strength suffer hydrogen embrittlement (HE) when corrosion takes place to the steels employed in humid conditions. ${ }^{1)}$ The phenomenon has been recognized for many years, and a lot of researches have been conducted to understand the mechanism and to propose the methods for protection to $\mathrm{HE}^{2-4)}$ Most of the researches have focused on the control of microstructure of the steel to prevent $\mathrm{HE}^{5)}$ or on the comprehension of diffusion kinetics of hydrogen in the steel to understand its mechanism. ${ }^{6}$ However, quite few approaches were conducted from the viewpoint of absorption reaction of hydrogen into the steel. Understanding hydrogen absorption process is also very important to suppress susceptibility of HE, and discovering the 'hydrogen-passive' surface that prevents hydrogen absorption into the steel provides possibility to avoid HE without any microstructural control. From the background, The Iron and Steel Institute of Japan (ISIJ) established the study group named 'Comprehensive

\footnotetext{
* Corresponding author: E-mail: haruna@kansai-u.ac.jp
}

Understanding of Hydrogen-Passive Surface on Steels for Prevention of Hydrogen Embrittlement' from 2013 to 2015 , and their findings have produced a lot of fundamental understandings for hydrogen adsorption of the steels. ${ }^{7}$ For example, a hydrogen concentration at the steel surface was determined in a quite short time after the hydrogen absorption condition was charged to the surface, a logarithm of the hydrogen concentration increased linearly with an increase in a steel hardness as well as in a reverse of a diffusion coefficient of hydrogen in the steel, and the hydrogen concentration decreased with a rise of cathodic potential but slightly increased with a rise of anodic potential. ${ }^{8,9)}$

On the other hand, it is also important to understand the hydrogen absorption into the steel during atmospheric corrosion, because high-strength steels often suffer HE during the usage in the open air. Some researchers have tried to monitor hydrogen absorption into the steels during atmospheric corrosion. Omura et al. ${ }^{10)}$ prepared the high-strength low-carbon steel on which an artificial sea water was splayed, conducted electrochemical hydrogen permeation tests to the specimen in the air with controlled RH and temperature, and revealed that a hydrogen permeation rate was a maximum at an $\mathrm{RH}$ 
of about $60 \%$. Li et al. ${ }^{11)}$ conducted similar hydrogen permeation tests as that by Omura et al. ${ }^{10)}$ to an Fe specimen with rust formed by the cyclic corrosion test, and revealed that a hydrogen permeation rate increased with increase in a cycle of the cyclic corrosion test. In addition, an $\mathrm{RH}$ at a maximum permeation rate was 98 and 50 for small and large cycle, respectively. However, there have been few researches on hydrogen absorption into the steels during atmospheric corrosion. Therefore, ISIJ has again established a study group of 'Corrosion-induced Hydrogen Absorption to Steels' since 2018 to understand the issue. In the group, our research group produced the system monitoring hydrogen permeation rate during atmospheric corrosion of an $\mathrm{Fe}$ specimen with rust layer in the humidity-controlled air, and investigated the effect of RH on hydrogen absorption during the corrosion.

\section{Experimental}

Material was Fe plate (Nilaco Co.) in $2 \mathrm{~mm}$ thickness and its purity was 99.5 mass\%. It was cut into specimens with shape of $40 \mathrm{~mm} \times 40 \mathrm{~mm}$. Surface of the specimen was mechanically polished by $\mathrm{SiC}$ papers to \#6/0 (corresponding to \#800) and then chemically polished in a solution mixing 46 mass $\%$ HF solution $(3 \mathrm{~mL})$ and deionized water (47 $\mathrm{mL})$ at room temperature for about $5 \mathrm{~s}$. The chemical polish was conducted to remove the deformed surface by the mechanical polishing. Thereafter, the specimen was rinsed in $3 \mathrm{kmol} \cdot \mathrm{m}^{-3} \mathrm{HCl}$ solution followed by deionized water.

One side of the specimen surface was covered with $\mathrm{Ni}$ by electro-plating in Watt bath $\left(250 \mathrm{~g} \cdot \mathrm{L}^{-1} \mathrm{NiSO}_{4} \cdot 6 \mathrm{H}_{2} \mathrm{O}, 45 \mathrm{~g} \cdot \mathrm{L}^{-1}\right.$ $\mathrm{NiCl}_{2} \cdot 6 \mathrm{H}_{2} \mathrm{O}, 40 \mathrm{~g} \cdot \mathrm{L}^{-1} \mathrm{H}_{3} \mathrm{BO}_{3}$ ) at room temperature. The specimen was immersed in the bath for $180 \mathrm{~s}$ and then subjected to the plating at $-10 \mathrm{~A} \cdot \mathrm{m}^{-2}$ for $420 \mathrm{~s}$ using a potentiostat (Model 2000, Toho Tech. Res. Co., Ltd) to obtain a plate with a thickness of about $15 \mathrm{~nm}$ recommended by Yoshizawa et al. ${ }^{12,13)}$ The other side of the specimen surface was covered with rust layer by wet/dry cyclic process. Some tiny droplets of $0.6 \mathrm{kmol} \cdot \mathrm{m}^{-3} \mathrm{NaCl}$ solution was set on the surface without Ni plate and naturally dried in air at room temperature. The process was repeated several times to form rust layer.

The specimen was subjected to an electrochemical hydrogen permeation test. The apparatus consisted of a Devanathan-Stachurski type double cells ${ }^{14)}$ as shown in Fig. 1. The left-hand side cell was for hydrogen absorption into the specimen. The cell had the two inlet and the two outlet lines. The two inlet lines were for injecting the dry air produced by silica gel as well as the RH-controlled air produced by mixing dry air and air through deionized water, respectively. Injection fluxes of both airs were the same as $1 \times$ $10^{-4} \mathrm{~m}^{3} \cdot \mathrm{s}^{-1}$. The right-hand side cell was for detection of hydrogen through the specimen, and its detail was described below. The specimen was set between the two cells. A test area of the specimen was $7.55 \times 10^{-4} \mathrm{~m}^{2}$. The Ni-plated surface was contacted to the hydrogen detection cell and the rust-layered surfaces was to the hydrogen absorption cell. The hydrogen detection cell had an $\mathrm{Ag} / \mathrm{AgCl}\left(3.3 \mathrm{kmol} \cdot \mathrm{m}^{-3}\right.$ $\mathrm{KCl})$ reference electrode and a $\mathrm{Pt}$ counter electrode. All the electrodes including the specimen were connected to a potentiostat (Model PS-12, Toho Tech. Res. Co., Ltd). A current of the Ni-plated surface was monitored in addition to an $\mathrm{RH}$ and a temperature in the hydrogen absorption cell

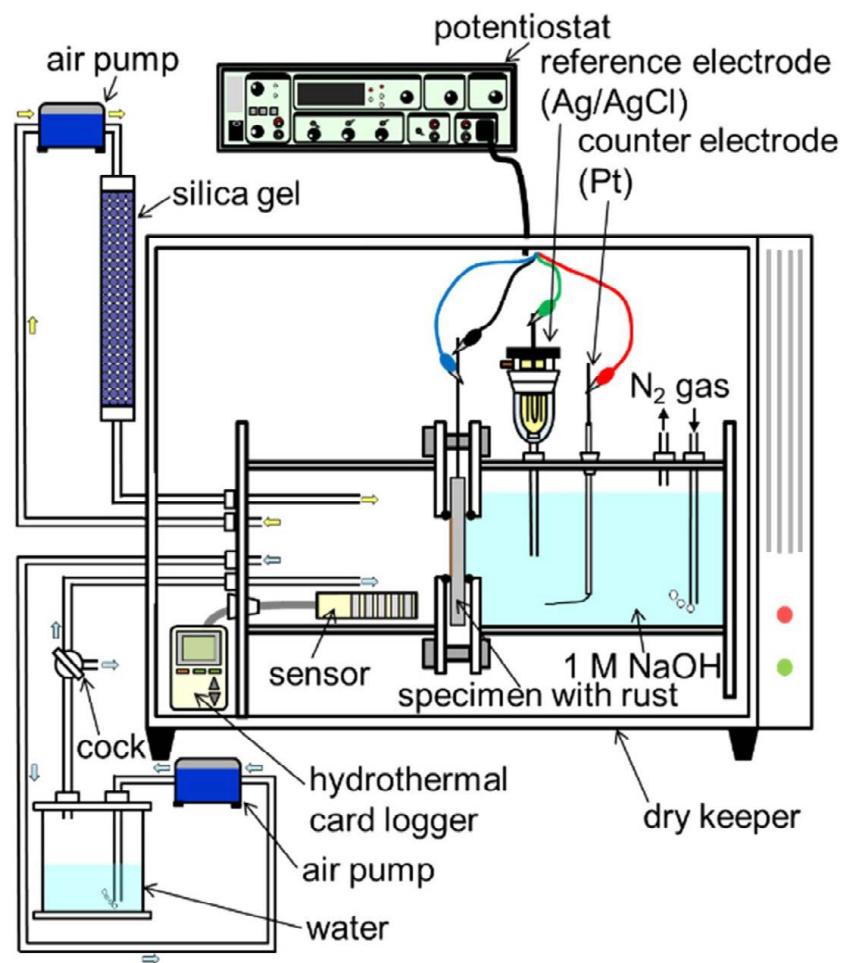

Fig. 1. Schematic illustration of a system for electrochemical hydrogen permeation test in atmospheric corrosion under controlled relative humidity (RH) and temperature. (Online version in color.)

during the test. First of all, the dry air was injected into the hydrogen absorption cell and $1.0 \mathrm{kmol} \cdot \mathrm{m}^{-3} \mathrm{NaOH}$ solution with sufficient deaeration was introduced into the hydrogen detection cell. A potential of $0.0 \mathrm{~V}_{\mathrm{Ag} / \mathrm{AgCl}}$ was applied to the Ni-plated surface, and maintained until a passivation current of Ni lowered to $100 \mathrm{nA}$ for detection of quite small current by hydrogen permeation. Thereafter, the RH-controlled air was injected into the hydrogen absorption cell to start atmospheric corrosion for the rusted surface of the specimen. As an $\mathrm{RH}$ and a current increased and then became stable, the dry air was again injected to stop the corrosion.

\section{Results}

As a typical example of the test results, Fig. 2 shows transients of an RH in the hydrogen absorption cell and a current density on the hydrogen detection surface of the specimen with rust layer. A target RH under the wet condition was $74 \%$. In the first stage when the rusted surface was in dry air, a small and stable passive current density of $\mathrm{Ni}$ was obtained. In the second stage when the humid air with the target $\mathrm{RH}$ was injected into the cell, an $\mathrm{RH}$ rapidly increased to the target value in about $10 \mathrm{ks}$ and maintained until the next stage. A current density started to increase about $7 \mathrm{ks}$ after an RH started to increase, and reached a stable value in about $20 \mathrm{ks}$. In the third stage when the dry air was again injected into the cell, an $\mathrm{RH}$ rapidly decreased to about $0 \%$ in about $10 \mathrm{ks}$, and maintained thereafter. A current density started to decrease at almost the same time as an RH started to decrease, and gradually reached a stable value coinciding to the initial passive current of Ni. Trends of the other test results using the humid airs with different RHs were similar to this result shown in Fig. 2. Hereafter, a steady value of 


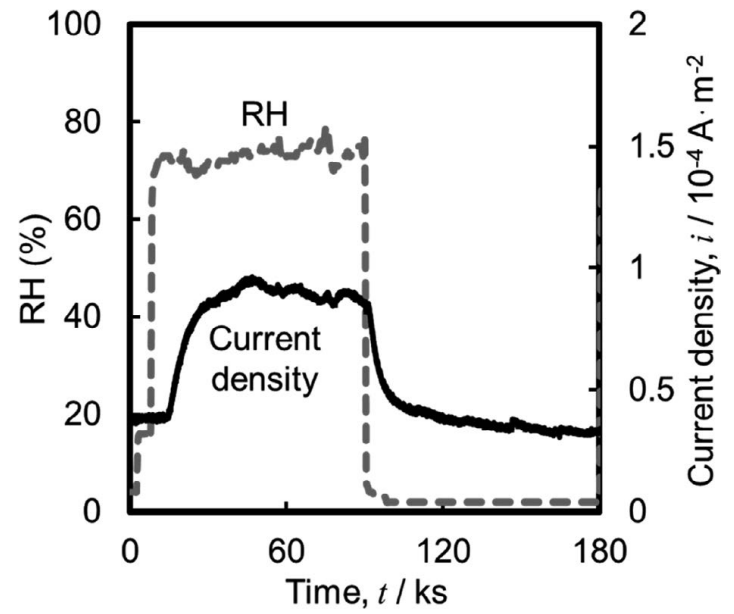

Fig. 2. Typical example of transients of an RH in the hydrogen absorption cell and a current density on the hydrogen detection surface of the specimen with rust layer.

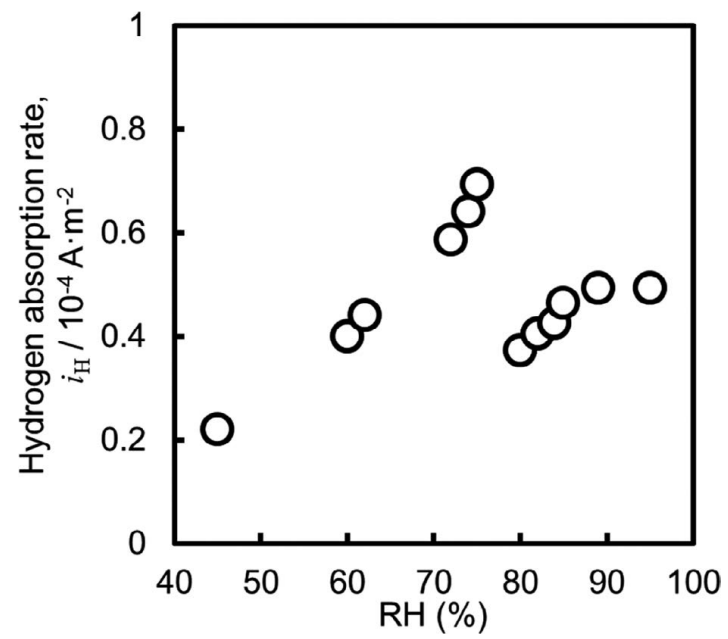

Fig. 3. Summary of relation between stable hydrogen absorption rate $\left(i_{\mathrm{H}}\right)$ and an $\mathrm{RH}$ under atmospheric corrosion.

hydrogen permeation rate $\left(i_{\mathrm{H}}\right)$ was determined by a difference between the stable current density in the second stage and that in the third stage.

From the results of the tests using the humid airs with different RHs, relation between a stable $\mathrm{RH}$ and an $i_{\mathrm{H}}$ was summarized in Fig. 3. It was found that an $i_{\mathrm{H}}$ increased with an increase in an RH between 42 and 74\%, suddenly decreased at $80 \%$, and again increased with an increase in an $\mathrm{RH}$ between 80 and $95 \%$.

\section{Discussion}

\subsection{Generation of Hydrogen Absorption}

In the electrochemical hydrogen permeation test, hydrogens generate on the Fe surface beneath the wet rust layer, and some of them absorb into the Fe bulk, diffuse toward the Ni-plated hydrogen detection surface, and is oxidized into proton on the surface in the $\mathrm{NaOH}$ solution. In the case that a steady-state current on the hydrogen detection surface is monitor during the wet condition, a flux of hydrogen $(J)$ is considered to be satisfied by Fick's first law,

$$
J=D C_{0} / L
$$

where, $D$ is a diffusion coefficient of hydrogen in the Fe substrate, $C_{0}$ is a hydrogen concentration at the hydrogen absorption surface of the substrate, and $L$ is a thickness of the substrate. In addition, a hydrogen concentration at the hydrogen detection surface is supposed to be zero because the hydrogens at the surface completely vanish by the oxidation. When an absorbing hydrogen $\left(\mathrm{H}_{\mathrm{ab}}\right)$ is oxidized on the hydrogen detection surface in the following reaction as,

$$
\mathrm{H}_{\mathrm{ab}} \rightarrow \mathrm{H}^{+}+\mathrm{e}^{-}
$$

an $i_{\mathrm{H}}$ is expressed as follows,

$$
i_{\mathrm{H}}=n F J=F D C_{0} / L
$$

where $n$ is number of electron per unity of reactant in the reaction equation ( $n=1$ in Eq. (2)) and $F$ is Faraday's constant. Since $L$ is almost a constant of about $2.0 \mathrm{~mm}$, Eq. (3) provides that $i_{\mathrm{H}}$ is positively proportional to $C_{0}$. A value of $C_{0}$ was not able to calculated here because $D$ was not determined.

It was pointed out in the previous reports ${ }^{8,9)}$ that a $C_{0}$ was fixed in a quite short time when the hydrogen absorption conditions (ex. applied cathodic potential) was newly set, and that a $C_{0}$ depended on the conditions. Under the condition of the stable $i_{\mathrm{H}}$ (corresponding to the stable $C_{0}$ ), a hydrogen absorption rate into the Fe substrate should be almost equal to a hydrogen desorption rate from the substrate, meaning that the following chemical reaction is in quasi-equilibrium state on the surface,

$$
\mathrm{H}_{\mathrm{ad}} \rightleftharpoons \mathrm{H}_{\mathrm{ab}}
$$

where $\mathrm{H}_{\mathrm{ad}}$ is an adsorbed hydrogen on the surface. Assuming that the hydrogen absorption rate $\left(v_{\mathrm{ab}}\right)$ and the hydrogen desorption rate $\left(v_{\mathrm{de}}\right)$ are expressed by the first order of a concentration as follows,

$$
\begin{gathered}
v_{\mathrm{ab}}=k_{\mathrm{ab}} \theta \\
v_{\mathrm{de}}=k_{\mathrm{de}} C_{0}
\end{gathered}
$$

and, the two rates should be equal, so that the following equation is satisfied as,

$$
k_{\mathrm{ab}} \theta=k_{\mathrm{de}} C_{0}
$$

where $k_{\mathrm{ab}}$ and $k_{\mathrm{de}}$ are rate constants, and $\theta$ is a coverage by $\mathrm{H}_{\mathrm{ad}}$ on the surface. Equations (3) and (7) provide, therefore, that increase in $i_{\mathrm{H}}$ require increase in $C_{0}$ and then increase in $\theta$.

Now considering two scenarios to increase $\theta$. Following two reactions are for producing $\mathrm{H}_{\mathrm{ad}}$ in general corrosion reactions.

$$
\begin{array}{r}
2 \mathrm{H}^{+}+2 \mathrm{e}^{-} \rightarrow 2 \mathrm{H}_{\mathrm{ad}} \cdots \cdots . . . \\
2 \mathrm{H}_{2} \mathrm{O}+2 \mathrm{e}^{-} \rightarrow 2 \mathrm{H}_{\mathrm{ad}}+2 \mathrm{OH}^{-}
\end{array}
$$

It is obvious that the two reaction are cathodic reaction, so that lowing potential promotes formation of $\mathrm{H}_{\mathrm{ad}}$ and then increase in $\theta$. If this first scenario to increase in $\theta$ is satisfied in the conditions under which $i_{\mathrm{H}}$ increases, the corrosion due to anodic reaction should be suppressed. On the other hand, the previous research ${ }^{15}$ ) was conducted to investigate the relation between a corrosion rate and an $\mathrm{RH}$ for a steel with rust layer during atmospheric corrosion under controlled humidity of air, and revealed that a corrosion rate increase 
with an increase in an $\mathrm{RH}$ up to $75 \%$, and then decreased. The previous and the present results suggest that increase in $i_{\mathrm{H}}$ corresponds to increase in corrosion rate, and that the above scenario is not satisfied in the atmospheric corrosion.

The second scenario is to increase $\mathrm{H}^{+}$concentration according to Eq. (8) because increase in $\mathrm{H}^{+}$concentration promotes formation of $\mathrm{H}_{\mathrm{ad}}{ }^{16)} \mathrm{In}$ order to confirm the apparent $\mathrm{pH}$ at the interface between the rust layer and the $\mathrm{Fe}$ surface under the wet conditions, following electrochemical hydrogen permeation test was conducted. A specimen was an as-polished Fe plate without rust layer, and the hydrogen absorption cell was filled with sulfuric acids with $\mathrm{pH} 2.9$, 3.7 and 4.7. The hydrogen absorption surface was naturally corroded in the acid solutions, and $i_{\mathrm{H}}$ was determined against each $\mathrm{pH}$. The other test conditions were the same as that described before. The results are summarized in Fig. 4. It was found from the figure that an $i_{\mathrm{H}}$ decreased exponentially with an increase in a $\mathrm{pH}$ in the tested $\mathrm{pH}$ region. The figure includes the results for the rusted specimen in the humid air, and the obtained $i_{\mathrm{H}}$ range was in a gray region. The corrosion potential of the rusted specimen during this atmospheric corrosion test is not determined. Assuming that the corrosion potentials of the specimens exposed in wet air and in acidic solution are not so far each other, the $\mathrm{pH}$ at the interface between the rust layer and the Fe substrate during the atmospheric corrosion is estimated to be a range from 4.2 to 4.3 , indicating relatively acidic condition. Akiyama et $a l .{ }^{17,18)}$ and Tsuru et al. ${ }^{19)}$ also pointed out that an increase in $i_{\mathrm{H}}$ during atmospheric corrosion was due to a decrease in $\mathrm{pH}$ inside the rust layer, and confirmed the value between 3 and 5 by a $\mathrm{W} / \mathrm{WO}_{3}$ electrode and by a glass $\mathrm{pH}$ electrode, respectively. The $\mathrm{pH}$ values were similar to our result.

Under atmospheric corrosion, following corrosion reaction are firstly considerable as;

Anodic reaction

$$
\begin{aligned}
\mathrm{Fe} & \rightarrow \mathrm{Fe}^{2+}+2 \mathrm{e}^{-} \\
(2 / 3) \mathrm{Fe} & \rightarrow(2 / 3) \mathrm{Fe}^{3+}+2 \mathrm{e}^{-}
\end{aligned}
$$

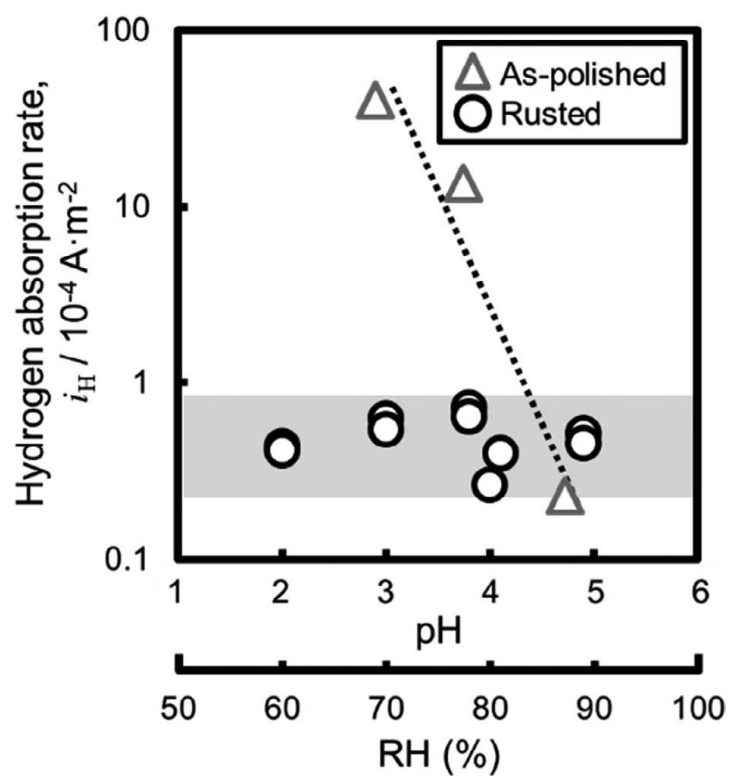

Fig. 4. Summary of relation between $i_{\mathrm{H}}$ and an $\mathrm{pH}$ under the condition of immersion in the solutions of different $\mathrm{pHs}$.
Cathodic reaction

$$
\begin{array}{r}
2 \mathrm{H}^{+}+2 \mathrm{e}^{-} \rightarrow 2 \mathrm{H}_{\mathrm{ad}} \\
2 \mathrm{H}_{2} \mathrm{O}+2 \mathrm{e}^{-} \rightarrow 2 \mathrm{H}_{\mathrm{ad}}+2 \mathrm{OH}^{-} \\
(1 / 2) \mathrm{O}_{2}+\mathrm{H}_{2} \mathrm{O}+2 \mathrm{e}^{-} \rightarrow 2 \mathrm{OH}^{-}
\end{array}
$$

On the basis of the reactions, promotion of the corrosion means higher $\mathrm{pH}$ condition to obtain smaller absorption rate of hydrogen. Whereas, when $\mathrm{NaCl}$ solid is exposed in wet air to form $\mathrm{NaCl}$ solution, a solution $\mathrm{pH}$ should be neutral. The processes cannot explain relatively low $\mathrm{pH}$ in the rust to produce large $i_{\mathrm{H}}$ during atmospheric corrosion.

Since the rust mainly consists of hydroxide, oxy-hydroxide and magnetite, some of considerable formation reactions of the substances were described as follows;

$$
\begin{aligned}
& \mathrm{Fe}^{2+}+2 \mathrm{OH}^{-} \rightarrow \mathrm{Fe}(\mathrm{OH})_{2} \\
& (2 / 3) \mathrm{Fe}^{3+}+2 \mathrm{OH}^{-} \rightarrow(2 / 3) \mathrm{Fe}(\mathrm{OH})_{3} \\
& \mathrm{Fe}^{2+}+2 \mathrm{H}_{2} \mathrm{O} \rightarrow \mathrm{Fe}(\mathrm{OH})_{2}+2 \mathrm{H}^{+} \\
& (2 / 3) \mathrm{Fe}^{3+}+2 \mathrm{H}_{2} \mathrm{O} \rightarrow(2 / 3) \mathrm{Fe}(\mathrm{OH})_{3}+2 \mathrm{H}^{+} \\
& (2 / 3) \mathrm{Fe}+(4 / 3) \mathrm{H}_{2} \mathrm{O} \rightarrow(2 / 3) \mathrm{FeOOH}+2 \mathrm{H}^{+}+2 \mathrm{e}^{-} \ldots \\
& (3 / 4) \mathrm{Fe}+\mathrm{H}_{2} \mathrm{O} \rightarrow(1 / 4) \mathrm{Fe}_{3} \mathrm{O}_{4}+2 \mathrm{H}^{+}+2 \mathrm{e}^{-} \\
& 2 \mathrm{Fe}^{2+}+4 \mathrm{H}_{2} \mathrm{O} \rightarrow 2 \mathrm{FeOOH}+6 \mathrm{H}^{+}+2 \mathrm{e}^{-} \\
& 3 \mathrm{Fe}^{2+}+4 \mathrm{H}_{2} \mathrm{O} \rightarrow \mathrm{Fe}_{3} \mathrm{O}_{4}+8 \mathrm{H}^{+}+2 \mathrm{e}^{-} \\
& (2 / 3) \mathrm{Fe}^{3+}+(4 / 3) \mathrm{H}_{2} \mathrm{O} \rightarrow(2 / 3) \mathrm{FeOOH}+2 \mathrm{H}^{+} . \\
& 6 \mathrm{Fe}^{3+}+8 \mathrm{H}_{2} \mathrm{O}+2 \mathrm{e}^{-} \rightarrow 2 \mathrm{Fe}_{3} \mathrm{O}_{4}+16 \mathrm{H}^{+}
\end{aligned}
$$

In the case that each of Eqs. (10) and (11) is electrochemically coupled with Eq. (12) at the same site during the corrosion, the solution in the rust is neutral because Eqs. (13) and (14) occurs to form $\mathrm{Fe}(\mathrm{OH})_{2}$ and $\mathrm{Fe}(\mathrm{OH})_{3}$, respectively. When a part amount of $\mathrm{Fe}^{2+}$ and $\mathrm{Fe}^{3+}$ generating by Eqs. (10) and (11) are directly reacted with $\mathrm{H}_{2} \mathrm{O}$ as Eqs. (15) and (16), respectively, $\mathrm{H}^{+}$as the products was reacted with $\mathrm{OH}^{-}$as a product of Eq. (12) to make solution neutral. Each of the two anodic reactions from $\mathrm{Fe}$ to the rust substances (i.e., $\mathrm{FeOOH}$ and $\mathrm{Fe}_{3} \mathrm{O}_{4}$ ) as Eqs. (17) and (18), respectively, is electrochemically coupled to Eq. (12) at the same site, then the solution is also neutral. However, each of the two anodic reactions from $\mathrm{Fe}^{2+}$ to the rust substances as Eqs. (19) and (20) is electrochemically coupled to Eq. (12) at the same site, then the solution is acidified. Whereas, no solution acidification takes place when a part of $\mathrm{Fe}^{3+}$ is reacted with $\mathrm{H}_{2} \mathrm{O}$ to form $\mathrm{FeOOH}$ as Eq. (21), because of neutralization of $\mathrm{H}^{+}$from Eq. (21) and $\mathrm{OH}^{-}$from Eq. (12). On the other hand, a cathodic reaction of Eq. (22) to form $\mathrm{Fe}_{3} \mathrm{O}_{4}$ from $\mathrm{Fe}^{3+}$ produced by Eqs. (11) and (12) may be concerned. When Eqs. (22), (10) and (13) are coupled to produce $\mathrm{Fe}(\mathrm{OH})_{2}$, the solution is neutral by including $\mathrm{OH}^{-}$ produced by Eqs. (11) and (12). Similarly, when Eqs. (22), (11) and (14) are coupled to produce $\mathrm{Fe}(\mathrm{OH})_{3}$, the solution is also neutral. Whereas, to produce $\mathrm{FeOOH}$ or $\mathrm{Fe}_{3} \mathrm{O}_{4}$, elec- 
trochemical coupling of Eq. (22) with each of Eqs. (17) and (18) makes the solution neutral, but with each of Eqs. (19) and (20) makes acidic. Therefore, in the case that the reactions concerned above take place homogeneously in the rust, it is summarized that the anodic reactions as Eqs. (19) and (20) are at least important to acidification of the solution in the rust. In addition, it is noted that acidification in the rust is considerable when separation of the sites for the cathodic reaction as Eq. (12) from the sites for the anodic reactions as Eqs. (10), (11), (17)-(20) as well as the cathodic reaction as Eq. (22) takes place outside and inside the rust, respectively.

\subsection{Effect of RH on Hydrogen Absorption Rate}

As described above, the specimen was an Fe plate with the rust layer which was produced by repeats of wet (put some $\mathrm{NaCl}$ solution droplets) and dry (exposure in air). In addition, Fig. 3 showed that $i_{\mathrm{H}}$ (proportional to $C_{0}$ ) increased with an increase in $\mathrm{RH}$ until $74 \%$, suddenly decreased at $80 \%$, and then increased again with an increase in RH until $95 \%$. For the trend, deliquescence of $\mathrm{NaCl}$ is considered as an important factor.

First, $\mathrm{NaCl}$ solid generates deliquescence to be $\mathrm{NaCl}$ solution in air with an RH more than $75 \%$ at $298 \mathrm{~K}$. At the $\mathrm{RH}$ of $75 \%$, an activity of water $\left(a_{\mathrm{H} 2 \mathrm{O}}\right)$ in air is equal to an $a_{\mathrm{H} 2 \mathrm{O}}$ in the $\mathrm{NaCl}$-saturated solution of $5.47 \mathrm{kmol} \cdot \mathrm{m}^{-3}$, that is, the transformation reactions between the liquid and the vapor phases of water is under equilibrium state. Second, when an $\mathrm{RH}$ is larger than $75 \%$, an $a_{\mathrm{H} 2 \mathrm{O}}$ in the air is larger than that in the saturated solution. The situation makes a concentration of water in the solution increase naturally to valance $a_{\mathrm{H} 2 \mathrm{O}}$ in the both phases. This means that a $\mathrm{NaCl}$ concentration is smaller. Third, when an $\mathrm{RH}$ is smaller than the deliquescence $\mathrm{RH}$ of $75 \%$, the $\mathrm{NaCl}$ solution generally transforms $\mathrm{NaCl}$ solid particles, producing dry condition in the rust, suggesting no corrosion. However, as shown in Fig. 3, an RH less than $75 \%$ still induced relatively large $i_{\mathrm{H}}$ owing to corrosion. There is another viewpoint on the equilibrium state between vapor water and liquid water droplet. For instance, transformation reaction between water vapor with an RH of $100 \%$ and water liquid having a flat surface is equilibrium state. When an RH is smaller than $100 \%$, most of water liquid evacuates but some semi-spherical water residues leave in general. The latter phenomenon explains that transformation reaction between water vapor with an RH less than $100 \%$ and water liquid having a curved surface is equilibrium state. The curvature of the water droplet is defined by an $\mathrm{RH}$ on the basis of Kelvin equation ${ }^{19,20)}$ as follows,

$$
\ln \mathrm{RH}=-2 \gamma V_{\mathrm{m}} /(r R T)
$$

where $\gamma$ is a surface tension, $V_{\mathrm{m}}$ is a mole volume, $r$ is a curvature of water liquid, $R$ is a gas constant and $T$ is an absolute temperature. Under Eq. (23) for pure water of $\gamma=$ $0.0728 \mathrm{~N} \cdot \mathrm{m}^{-1}, V_{\mathrm{m}}=1.80 \times 10^{-5} \mathrm{~m}^{-3} \cdot \mathrm{mol}, R=8.314$ $\mathrm{J} \cdot(\mathrm{mol} \cdot \mathrm{K})^{-1}$ and $T=298 \mathrm{~K}$, RHs of 10,99 and $100 \%$ leads to water radii of $0.005,1.0 \mathrm{~nm}$ and a positive infinity (i.e., flat), respectively. The phenomenon is expected to be applicable to the droplets of saturated- $\mathrm{NaCl}$ solution in the rust layer because it is confirmed that the rust layer of a steel has a lot of pores of size in nm order. ${ }^{22-24)}$ Therefore, the following points are considered to be important to the atmospheric corrosion as;

Size of droplets of saturated $\mathrm{NaCl}$ solution depending on an $\mathrm{RH}$ below $75 \%$

Deliquescence of $\mathrm{NaCl}$ at the $\mathrm{RH}$ of $75 \%$

Concentration of $\mathrm{NaCl}$ solution depending on an $\mathrm{RH}$ beyond $75 \%$

Now, it is tried to explain the results shown in Fig. 3 using schematic illustration on the corrosion model as shown in Fig. 5. Hereafter, it is considered that acceleration of corrosion reaction generates enhancement of acidity of the solution at the rust/Fe interface, followed by enlargement of $C_{0}$ and the $i_{\mathrm{H}}$, as described in Section 4.1.

In the range of $\mathrm{RH}$ less than $75 \%$, the rust layer should include no $\mathrm{NaCl}$ solution but $\mathrm{NaCl}$ solid particle and tiny water droplets because of the air condition without deliquescence of $\mathrm{NaCl}$. The condition should be hard to occur corrosion followed by hydrogen absorption. However, a finite $i_{\mathrm{H}}$ was actually measured and increased with an increase in an $\mathrm{RH}$ in the present tests. The result suggests corrosion and then existence of $\mathrm{NaCl}$ solution. Assuming that Kelvin equation is applicable to the saturated- $\mathrm{NaCl}$ solution, the tiny and saturated solution droplets exist in the rust layer, and a radius of the droplet may be or less than that limited by an RH. Since it is confirmed that there are a lot of pores with several orders of nm in rust layer, ${ }^{22-24)}$ it is guessed that the droplets are in the pores and on the substrate. Therefore, it is considered that increase in an RH induces increase in a radius of the saturated droplets, increase in a total contact area of the droplets to the substrate, increase in a corrosion rate multiplied by the area, and then increase in an $i_{\mathrm{H}}$. The Fe substrate may not be fully covered with the droplets, so that oxygen can easily reaches the substrate to be used for the corrosion.
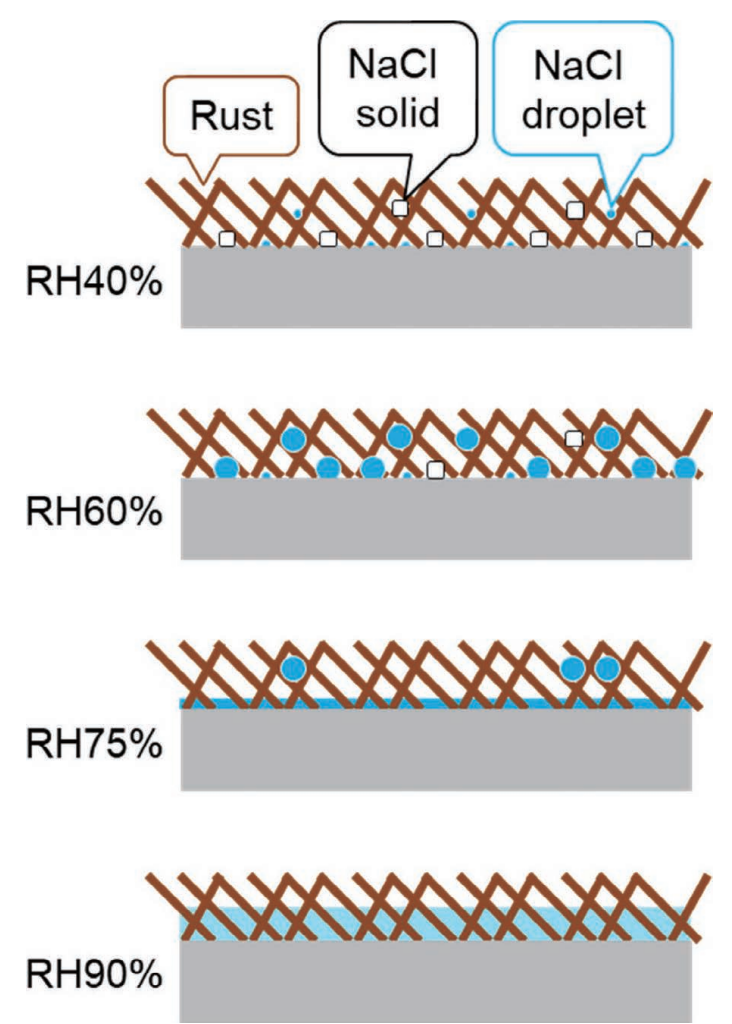

Fig. 5. Schematic illustrations of the rust layer including $\mathrm{NaCl}$ solution depending on an RH. 
At the $\mathrm{RH}$ of $75 \%$, all $\mathrm{NaCl}$ solid particles generate deliquescence to form a lot of the saturated- $\mathrm{NaCl}$ solution in and over the rust layer. The saturated solution has a quite small concentration of dissolved oxygen of $5.3 \times 10^{-5}$ $\left.\mathrm{kmol} \cdot \mathrm{m}^{-3}, 25\right) 0.2$ times of the one in 3.0 mass $\% \mathrm{NaCl}$ solution. The solution may, therefore, covered the Fe substance, become a barrier against oxygen supply, suddenly suppress the corrosion, and then suppress the hydrogen absorption.

In the range of $\mathrm{RH}$ more than $75 \%$, increase in an $\mathrm{RH}$ induces decrease in an $\mathrm{NaCl}$ concentration as explained above. In this case, the following three things are known in general: First, increase in an $\mathrm{NaCl}$ concentration induces increase in a thickness of the $\mathrm{NaCl}$ solution layer. Second, increase in an $\mathrm{NaCl}$ concentration induces increase in a concentration of dissolved oxygen. Third, the corrosion rate of steels under solution layer is controlled by diffusion flux of oxygen $\left(J_{\mathrm{O} 2}\right)$ through the solution layer on the basis of Fick's first law as follows,

$$
J_{\mathrm{O} 2}=D_{\mathrm{O} 2} C_{\mathrm{O} 2} / \delta
$$

where, $D_{\mathrm{O} 2}$ is a diffusion coefficient of oxygen in the solution, $C_{\mathrm{O} 2}$ is a concentration of dissolved oxygen at the outer surface of the solution layer, and $\delta$ is a thickness of the solution layer (when $\delta$ is larger than $\delta_{0}$ (c.a., $0.4 \mathrm{~mm}$ ), $\delta$ replaces into $\delta_{0}$ ). The equation informs that increase in $J_{\mathrm{O} 2}$ is resulted from increase in $C_{\mathrm{O} 2}$ and/or decrease in $\delta$ because $D_{\mathrm{O} 2}$ is independent of $C_{\mathrm{O} 2}$ and $\delta$. It is revealed from the present result in Fig. 3 that increase in an RH beyond 75\% induced increase in an $i_{\mathrm{H}}$, meaning increase in a corrosion rate and then increase in a $J_{\mathrm{O} 2}$. The consideration suggests that increase in an $i_{\mathrm{H}}$ with an increase in an $\mathrm{RH}$ is more strongly controlled by increase in an $C_{\mathrm{O} 2}$ with an increase in an RH due to dilution of the solution layer.

\section{Conclusions}

The research aimed to detect the rate of hydrogen absorption into $\mathrm{Fe}$ with rust layer containing $\mathrm{NaCl}$ during atmospheric corrosion under controlled RH and temperature, and to reveal the effect of RH on the hydrogen absorption rate. Thereafter, the following findings are obtained.

- In the region of RH between 40 and $74 \%$, a hydrogen absorption rate increased with an increase in an RH. It was supposed that some of $\mathrm{NaCl}$ solids are deliquescent into tiny and $\mathrm{NaCl}$-saturated solution droplets in the rust layer, and the radius of the droplet increases with an increase in an RH. In this case, it was considered that increase in an RH induces increase in a contact area of $\mathrm{Fe}$ with the droplets, increase in a corrosion rate, and then increase in a hydrogen absorption rate.

- At the RH slightly over $75 \%$, a hydrogen absorption rate suddenly decreased. It is supposed that complete deliquescence of $\mathrm{NaCl}$ solids takes place and that the a lot of saturated $\mathrm{NaCl}$ solution containing oxygen of quite small concentration is formed in the rust layer. In this case, it was considered that the saturated solution suddenly covers on the Fe substrate as a barrier against oxygen supply, and the corrosion as well as the hydrogen absorption are suppressed.

- In the region of RH between 80 to $95 \%$, a hydrogen absorption rate again increased with an increase in an $\mathrm{RH}$. It was supposed that corrosion rate is controlled by diffusion flux of oxygen into the solution layer, and the $\mathrm{NaCl}$ concentration of the solution layer decreases with an increase in an RH. In this case, it was considered that the concentration of oxygen in the solution layer increases with an increase in an $\mathrm{RH}$, and the corrosion as well as the hydrogen absorption are enhanced.

- The values of $\mathrm{pH}$ in the rust layers during the atmospheric corrosion in the air with an RH between 40 to $95 \%$ were estimated to be 4.2 and 4.3 , slightly acidic. It was considered that the acidification is resulted at least from the anodic reactions from $\mathrm{Fe}^{2+}$ to $\mathrm{Fe}_{3} \mathrm{O}_{4}$ or $\mathrm{FeOOH}$ accompanied with cathodic reaction of oxygen at the same site, and/or from separation of the sites for anodic reactions to form the rust substances from the site for the cathodic reaction of oxygen.

\section{Acknowledgements}

One of the authors thanks the study groups, "Comprehensive Understanding of Hydrogen-Passive Surface on Steels for Prevention of Hydrogen Embrittlement" from 2013 to 2015 and "Corrosion-induced Hydrogen Absorption to Steels" since 2018 in Iron and Steel Institute of Japan for sufficient discussion to our research results and a part of financial support. In addition, One of the authors thanks Grant-in-Aid for Scientific Research (C) (18K04784) of JSPS and Kansai University Fund for Domestic and Overseas Research Fund for a part of financial support.

\section{REFERENCES}

1) S. Matsuyama: Tetsu-to-Hagané, 80 (1994), 679 (in Japanese)

2) Proc. Conf. of Fundamental Aspects of Stress Corrosion Cracking, ed. by R. W. Staehle, National Association of Corrosion Engineers (NACE), Houston, TX, (1969).

3) Int. Conf. on Stress Corrosion Cracking and Hydrogen Embrittlement of Iron Base Alloys, ed. by R. W. Staehle, J. Hochmann, R. D. McCright and J. E. Slater, NACE, Houston, TX, (1977).

4) M. Nagumo: Suisozeisei no Kiso, Uchida Rokakuho, Tokyo, (2008), (in Japanese).

5) H. Asahi, D. Hirakami and S. Yamasaki: ISIJ Int., 43 (2003), 527.

6) T. Depover, E. Wallaert and K. Verbeken: Mater. Sci. Eng. A, 649 (2016), 201

7) M. Sakairi: ISIJ Int., 56 (2016), 377.

8) T. Haruna, K. Takeuchi, T. Kasahara and Y. Nii: ISIJ Int., 56 (2016), 378.

9) T. Haruna and Y. Nii: ISIJ Int., 56 (2016), 392.

10) T. Omura, T. Kushida, T. Kudo, F. Nakasato and S. Watanabe: Zairyo-to-Kankyo, 54 (2005), 61 (in Japanese).

11) S. Li, E. Akiyama, T. Shinohara, K. Matsuoka and W. Oshikawa: Tetsu-to-Hagané, 99 (2013), 651 (in Japanese).

12) S. Yoshizawa and K. Yamakawa: Corros. Eng., 24 (1975), 365 (in Japanese).

13) S. Yoshizawa, T. Tsuruta and K. Yamakawa: Corros. Eng., 24 (1975), 511 (in Japanese).

14) M. A. V. Devanathan and Z. Stachurski: Proc. R. Soc. Lond. A, 270 (1962), 90.

15) S. Takagi, Y. Shoji, T. Haruna, K. Kashima, T. Kamimura and H. Miyuki: CAMP-ISIJ, 26 (2013), 962 (in Japanese).

16) J. F. Newman and L. L. Shreir: Corros. Sci., 9 (1969), 631.

17) E. Akiyama, K. Matsukado, M. Wang and K. Tsuzaki: Corros. Sci., 52 (2010), 2758

18) E. Akiyama, S. Li, T. Shinohara, Z. Zhang and K. Tsuzaki: Electrochim. Acta, 56 (2011), 1799.

19) T. Tsuru, Y. Huang, M. R. Ali and A. Nishikata: Corros. Sci., 47 (2005), 2431

20) W. Thomson: Proc. R. Soc. Edinb., 7 (1872), 63.

$21)$ W. Thomson: Lond. Edinb. Dublin Philos. Mag. J. Sci., 42 (1871), No. 282, 448.

22) T. Ishikawa, A. Maeda, K. Kandori and A. Tahara: Corrosion, 62 (2006), 559.

23) T. Ishikawa, T. Yoshida, K. Kandori, T. Nakayama and S. Hara: Corros. Sci., 49 (2007), 1468.

24) T. Komori, W. Tanimoto, K. Kyono and H. Nakano: Zairyo-toKankyo, 62 (2013), 495 (in Japanese).

25) Y. Hisamatsu and H. Omori: Corros. Eng. Dig., 9 (1960), 481 (in Japanese). 